\title{
A Platform Approach in Solution Business: How Platform Openness can be Used to Control Solution Networks.
}

Ruiqi Wei

$U C D$

Susi Geiger

$U C D$

Roisin Vize

TU Dublin, roisin.vize@tudublin.ie

Follow this and additional works at: https://arrow.tudublin.ie/buschmarart

Part of the E-Commerce Commons, and the Marketing Commons

\section{Recommended Citation}

Wei, R., Geiger, S., Vize, R. (2019) A Platform Approach in Solution Business: How Platform Openness can be Used to Control Solution Networks, Industrial Marketing Management, https://doi.org/10.1016/ j.indmarman.2019.04.010Industrial Marketing Management

This Article is brought to you for free and open access by the School of Marketing at ARROW@TU Dublin. It has been accepted for inclusion in Articles by an authorized administrator of ARROW@TU Dublin. For more information, please contact arrow.admin@tudublin.ie, aisling.coyne@tudublin.ie,gerard.connolly@tudublin.ie.

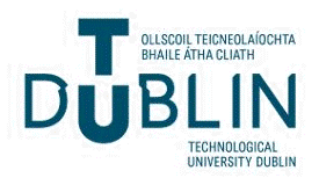


Research paper

\title{
A platform approach in solution business: How platform openness can be used to control solution networks
}

\author{
Ruiqi Wei ${ }^{\mathrm{a}, *}$, Susi Geiger ${ }^{\mathrm{a}}$, Róisín Vize ${ }^{\mathrm{b}}$ \\ ${ }^{a}$ Smurfit School of Business, University College Dublin, Blackrock, Dublin 4, Ireland \\ ${ }^{\mathrm{b}}$ College of Business, Technological University Dublin, Aungier Street, Dublin, Ireland
}

\section{A R T I C L E I N F O}

\section{Keywords:}

Solution business

Digital platforms

Control

Network orchestration

B2B solutions

Modularity

\begin{abstract}
A B S T R A C T
This paper explores how customer solution providers leverage digital platform architectures and particularly platform openness to exert control over complex organizational networks. A multiple case-study approach studies three companies with digital platforms that orchestrate solution networks in the LED and ICT industries. Our findings show that the features of product modules (core or peripheral), service modules (relationship intensity and customization), and knowledge modules (explicit, tacit and codified) have differential influence on the levels of platform openness. By managing platform openness of different subsystems accordingly, the solution providers can achieve different control benefits, including ensuring module quality, increasing offering variety, reducing dependence on module providers, and facilitating resource sharing. We contribute to the literature on solution business by reconceptualising the platform approach from a two-level perspective. We also deepen the field's understanding of the role of digital platforms in solution business from an architectural perspective.
\end{abstract}

\section{Introduction}

How should a focal firm orchestrate its network partners, and how much control is needed in this process? This is an enduring question in business-to-business (B2B) research, and it is one that has attained heightened relevance in an era where digital platforms in industrial networks proliferate (e.g. Eloranta \& Turunen, 2016; Perks, Kowalkowski, Witell, \& Gustafsson, 2017). This paper examines how solution providers leverage digital platform openness to control solution networks. Drawing together research from the information systems and networks literatures, we investigate conceptually and empirically how platform openness can be managed by the focal firm through module features and how openness and module features interact at interfirm and solution levels to attain control benefits.

Increasing specialization and higher degrees of knowledge intensiveness in B2B markets have led many business suppliers to develop solutions in the shape of customized, needs-specific combinations of products and services (e.g. Davies, Brady, \& Hobday, 2007; Nordin \& Kowalkowski, 2010). The provision of these solutions often requires a network of external complementors to achieve service scope and capabilities in line with buyers' requirements (Gebauer, Paiola, \& Saccani,
2013; Kindström \& Kowalkowski, 2014). Network orchestration is the process of assembling and managing an interorganizational network to support those tasks that are beyond the company's own capabilities (Frankenberger, Weiblen, \& Gassmann, 2013; Paquin \& HowardGrenville, 2013). As the network expands, it often becomes increasingly difficult to orchestrate. For example, as the number of suppliers increases they typically become more diverse (Choi \& Krause, 2006), relationships can vary due to vertical disintegration (Hobday, Davies, \& Prencipe, 2005), and heterogeneity of products and services leads to increasing complexity in delivering a customized solution.

Recent research in B2B marketing has proposed that solution providers can overcome the challenges of network complexity by adopting a platform approach to network orchestration (Bask, Lipponen, Rajahonka, \& Tinnilä, 2010; Eloranta \& Turunen, 2016; Pekkarinen \& Ulkuniemi, 2008; Storbacka, 2011). A platform approach leverages the value of digital technologies based on IT-enabled interactions (Thomas, Autio, \& Gann, 2014). The core of the platform consists of a modular structure that allows the firm to generate a wide configuration of product-service solutions characterized by easily interchanged modules (Meyer \& Lehnerd, 1997). Research has begun to explore the use of a modular structure in solution business (Salonen, Rajala, \& Virtanen,

\footnotetext{
* Corresponding author at: Carysfort Avenue, Blackrock, Dubiln 4, Ireland.

E-mail address: ruiqi.wei@ucdconnect.ie (R. Wei).
} 
2018). ${ }^{1}$ Past research has investigated product, service and knowledge features that influence interfirm coordination where digital platforms are not involved (e.g. Brusoni \& Prencipe, 2001; Saccani, Visintin, \& Rapaccini, 2014; Valtakoski, 2017; Windahl \& Lakemond, 2010). Several studies have also recognized the importance of digital platforms in orchestrating solution networks (Eloranta \& Turunen, 2016; Perks et al., 2017). Yet, limited research has combined insights on modular structures with a digital platform perspective in solution business.

This paper proposes to fill this gap by adopting an architectural perspective of platforms, focusing on how platform openness and control can be balanced. With this aim, we borrow from literature in information systems (IS) on digital infrastructures to complement and expand B2B marketing research. An architectural perspective in platform contexts assumes that platform structures are the result of deliberate design decisions on a system of elements and their relationships (Thomas et al., 2014). A platform reflects sets of decisions on the level of modularization, openness, and information disclosure (Cusumano \& Gawer, 2002; Richard \& Devinney, 2005; Tiwana, Konsynski, \& Bush, 2010). Architectures in platform contexts show different levels of openness to participation by different parties (Thomas et al., 2014). Taking an architectural perspective on digital infrastructures allows us to understand how the platform architecture offers control points in interfirm coordination (Tilson, Lyytinen, \& Sørensen, 2010) and what design decisions managers may take as a result of these insights. Digital infrastructures form a common structure consisting of subsystems (e.g. Gawer, 2014; Thomas et al., 2014; Tiwana \& Konsynski, 2010). The IS literature has suggested that managing the level of openness of subsystems can have controlling effects in large loosely-coupled networks (e.g. West \& O'Mahony (2008)). ${ }^{2}$ Opening a platform can enhance the diversity and innovativeness of complementors (Gawer, 2014). However, it also means relinquishing some control to third-parties, which may lead to lower efficiency, quality uncertainty and the loss of integrity (Boudreau, 2010, 2012). Therefore, it is vital for solution providers to manage platform openness and efficiently balance control and autonomy in networked solution provision.

Adopting an architectural perspective, this paper suggests that openness can be managed through careful design of product, service and knowledge modules and their interactions. It explores how different modules features, namely, specific characteristics of product, service and knowledge and combinations thereof, can influence platform openness and influence interfirm coordination. We present a multiple case-study approach to explore our research questions (Yin, 2003): how can focal firms orchestrate complex solution networks through their digital platform architecture? Specifically, how can they manage platform openness through module features? And how do openness and module features interact at interfirm and solution levels for control benefits? Overall, our research contributes to the solution business literature by reconceptualizing the platform approach from a two-level perspective. From an architectural perspective, this research not only confirms the importance of modular solution design but also reveals how the features of different modules influence interfirm coordination and the design of platform architecture. More generally, this study contributes to the literature on B2B networks by explaining how lead firms can leverage the platform architecture and control platform openness to orchestrate $\mathrm{B} 2 \mathrm{~B}$ networks. It also contributes to the platform literature by reconceptualizing platform openness in a solution network context, thereby placing the issue of complexity at the network rather than the solution level. Finally, our propositions provide an

\footnotetext{
${ }^{1}$ Modularity refers to "building a complex product or process from smaller subsystems that can be designed independently yet function together as a whole" (Baldwin \& Clark, 1997, p.84).

${ }^{2}$ Following Boudreau (2010), we define platform openness as the level of restrictions on the use, development and commercialization of a module in a subsystem.
}

empirically grounded basis for future research on digital solution platforms in a B2B context.

\section{Theoretical framework}

In this paper we draw on two bodies of work that we bring together in our theoretical framework: work on platforms from an IS perspective and research on solution networks from a B2B marketing perspective. This section will offer a brief overview of both before defining in more detail our architectural perspective. Specifically, we elaborate on the characteristics of product, service and knowledge modules and platform openness respectively. We bring these strands of argument together in a theoretical framework (Fig. 1), which guides our empirical work.

\subsection{A platform approach in solution business}

According to platform thinking (Sawhney, 1998), the objective of platforms is to increase the variety of offerings - products, services or solutions - without increasing the complexity of internal structures. The mechanism behind this is modularity, which emerged from manufacturing and diffused to industrial services with the automation of service processes and the increasing use of information technology (IT) in business service delivery (Bask et al., 2010). The basic premise of modularity is that complex products or processes can be broken down and built up through smaller subsystems, which can be flexibly combined (Baldwin \& Clark, 1997). In the modularity literature, a platform approach signals the existence of a modular structure that will allow the firm to develop a wide portfolio of solutions through easily interchangeable modules brought or held together by a common platform (Meyer \& Lehnerd, 1997).

As illustrated in Table 1, recent research in B2B marketing has started to explore how a platform approach may help develop and deliver customer solutions. Pekkarinen and Ulkuniemi (2008) conceptualized the platform approach as a systematic way to develop and deliver customized solutions efficiently by reconfiguring different modules and those functional units that are responsible for them. This conceptualization of solution components as modules has been deepened in several industrial marketing studies, which Table 1 summarizes. Most recently, it has been extended to include knowledge as modules in customer solutions (Valtakoski, 2017). While emphasizing the value creation and creative potential inherent in a modular structure, this research cautions that the heterogeneity of modules may lead to high levels of platform complexity (Bask et al., 2010). However, to our knowledge researchers have not specifically focused on the question of how this innovative potential may be managed across complementor firms through deliberate design choices, nor have they considered the differential effects of different modules (products, services and knowledge) in controlling complexity.

In a parallel effort to this modularization research, a handful of studies have begun to focus on how to leverage information technologies and digital platforms to connect diverse actors in solution businesses from an organizational perspective. The role of digital platforms has thereby been extended from coordinating internal units (e.g. Cenamor, Sjödin, \& Parida, 2017; Coreynen, Matthyssens, \& Van Bockhaven, 2017; Storbacka, 2011) to orchestrating external networks (e.g. Eloranta \& Turunen, 2016; Perks et al., 2017). Eloranta and Turunen (2016) for instance see digital platforms as an ICT-enabled environment in which "networked operations could take place" and that represents "a practical and virtual place to meet" for networked solution members (p.182). Building on their work, Perks et al. (2017) argue that platforms are dynamic configurations of tangible resources (technical architecture) and intangible resources (organizational norms, rules and activities), based on which network members cocreate value. Thus, these studies have started to recognize the orchestration roles of digital platforms in developing and delivering solutions from an internal and a network perspective. They also suggest that 


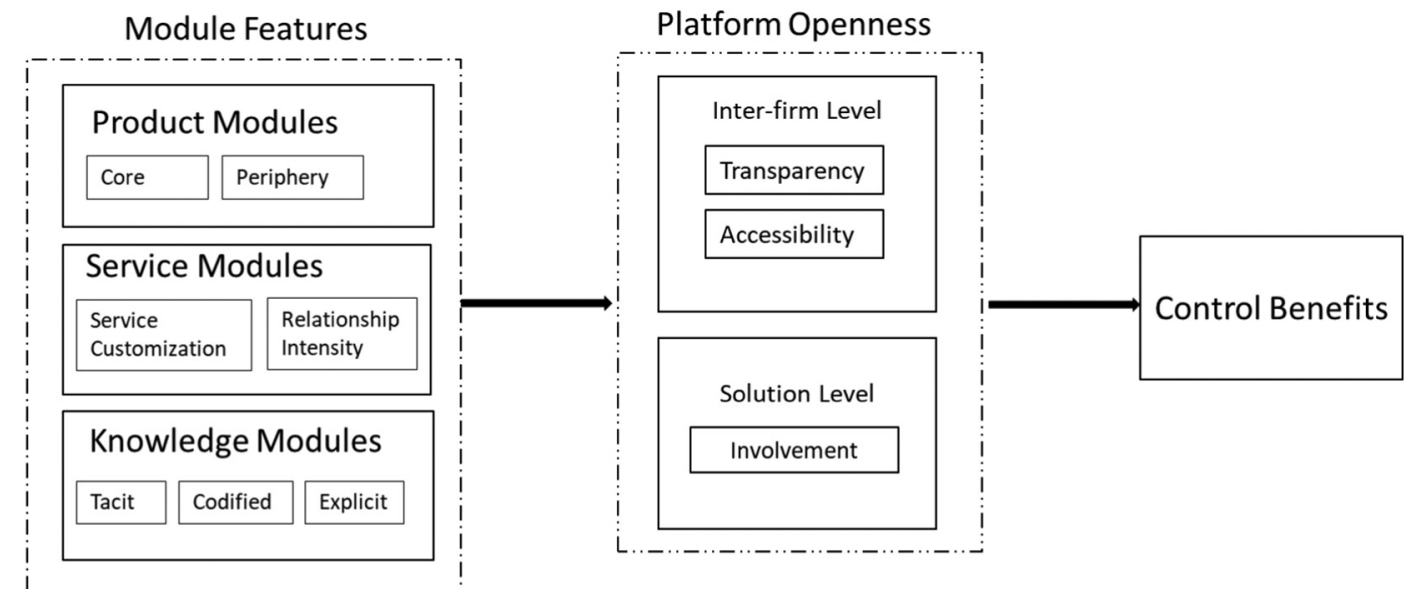

Fig. 1. Theoretical framework.

digital platforms in solution business can complement a modular solution structure in reconfiguring different modules and partners to pursue both customization and operational efficiency. What is missing from these analytical forays is a focus on how architectural choices influence control and autonomy in network orchestration, which - according to the IS literature - may have important control benefits in interfirm coordination. Thus, while we acknowledge the advances made in B2B marketing research in recent years, there is a clear need to combine extant research with a deeper focus on the design choices to be made in adopting digital infrastructures.

\subsection{The importance of platform architecture}

Turning to the IS literature provides us with further insights into the architectural perspective of designing digital infrastructures, which solution business research can draw on. In IS research, digital infrastructures often refer to "a collection of information technologies and systems that jointly produce a desired outcome" (Henfridsson \& Bygstad, 2013, p. 909). For example, enterprise resource planning systems, online marketplaces, and customer relationship management systems are all connected with each other and form digital infrastructures. These infrastructures form a common structure consisting of subsystems capable of dividing a platform's participants with different resources and capabilities into subsystems (e.g. Gawer, 2014; Thomas et al., 2014; Tiwana \& Konsynski, 2010). In a situation where a digital platform facilitating solution network coordination adopts a modular structure, which consists of different subsystems, we argue that changing the openness of these subsystems may help a solution provider exert control over its solution networks. This section develops this argument in more detail. It introduces a theoretical framework to guide our exploration into modularity and platform openness by specifying different characteristics of product, service and solution modules. Leaning on the IS literature, the section then proceeds to define platform openness and control benefits.

\subsubsection{Module features}

To recall, we follow Baldwin and Clark (1997, p.84) in defining modularity as "a complex product or process from smaller subsystems that can be designed independently yet function together as a whole". Accordingly, "a module is a unit whose structural elements are powerfully connected among themselves and relatively weakly connected to elements in other units" (Baldwin \& Clark, 2000, p. 63). As discussed previously, a solution includes product, service and knowledge modules, and in this section, we will explore those module features that may influence interfirm coordination.

For products, the platform literature typically distinguishes between core and peripheral product modules (Baldwin \& Woodard, 2008). A core product module can influence a large proportion of other product modules (Gawer \& Cusumano, 2008) while peripheral product modules can increase the variety of the offerings (Baldwin \& Woodard, 2008). For example, if a solution is to develop a customized computer system for a technology company, core product modules may be central processing units (CPUs) and peripheral product modules can be hard drives, flash drives etc. The modularity literature implies that whether a product is core or peripheral influences interfirm coordination (e.g.Brusoni \& Prencipe, 2001; Schilling, 2000). For example, solution providers may tend to keep core modules in-house while outsourcing peripheral modules (Brusoni \& Prencipe, 2001; Schilling, 2000). Therefore, in this research two features of product modules - core and peripheral - will be considered in the analysis.

In the solution business literature, products and services are two intrinsic parts in a solution offering (Brax \& Jonsson, 2009; Davies et al., 2007; Davies, Brady, \& Hobday, 2006), and many services can be perceived as products. However, from a modular perspective it is necessary to distinguish services from products in a solution due to the near-simultaneity of production and consumption of services as opposed to products (Grönroos, 1990). Therefore, a service module is considered as a process or its core is process-based (Brax \& Jonsson, 2009; Voss \& Hsuan, 2009).

While services have been categorized in various ways in a solution business context, we focus on the service characteristics of customization and relationship intensity. Saccani et al. (2014) found that services have different degrees of customization and relationship intensity, and that these characteristics influence both provider-buyer relationships and process issues. For example, information exchange between customers and providers is limited in services with low relationship intensity and low customisation, while information exchange is at a significant level in services with high relationship intensity (ibid.). Since these characteristics influence provider-buyer relationships in services, we will explore degrees of customization and relationship intensity as the pertinent features of service modules.

Finally, due to the importance of knowledge resources in solutions, recent research considers knowledge as modules that can be distinguished from 'normal' services (e.g. Storbacka, 2011; Valtakoski, 2017). Following Ardolino et al.'s (2018) study on digital technologies' impact on knowledge generation in service transformation, we apply Rowley's (2007) definition of knowledge as the combination of information that - through adding expert opinion, understanding, accumulated learning and experience - leads to valuable insights, know-how and actionable guidance. While previous research has emphasized the importance of knowledge management in solution business (Johnstone, Dainty, \& Wilkinson, 2009; Pawar, Beltagui, \& Riedel, 2009), research has mainly focused on knowledge sharing activities as a type of services (e.g. Aarikka-Stenroos \& Jaakkola, 2012; Muller \& Zenker, 2001). 


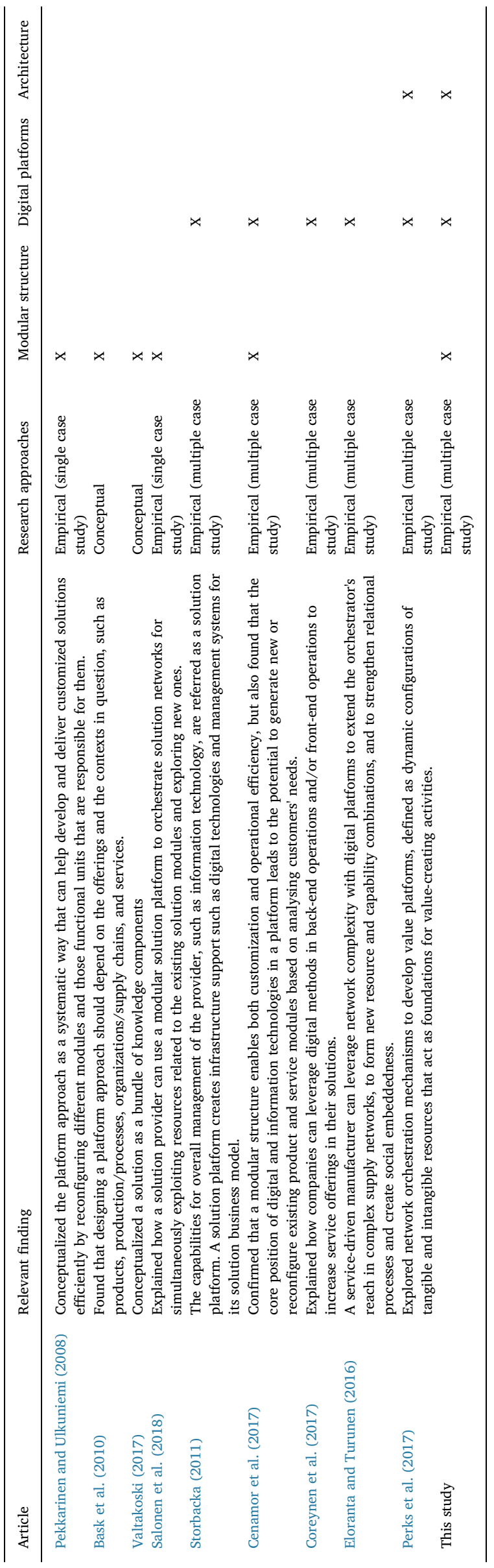

However, in a platform approach, knowledge may not come from a solution provider itself but from diverse network partners (Salonen \& Jaakkola, 2015). Since different knowledge characteristics have different impacts on interfirm coordination in knowledge transfer (Valtakoski, 2017), it is essential to consider knowledge as modules.

Valtakoski (2017) categorises knowledge into four distinct types: (1) knowledge embodied in physical products, (2) intangible yet codified knowledge, such as data analysis about market trends, (3) tacit knowledge, such as the know-how of experts, and (4) explicit knowledge such as industry reports. These knowledge characteristics may influence interfirm coordination. For example, tacit knowledge transfer requires close interactions between the firms (Simonin, 1999), while codified knowledge requires loose interactions. Explicit knowledge can be transferred in the form of standardized, commonly understood codes and therefore requires less collaboration (Valtakoski, 2017). While Cenamor et al. (2017) have considered information as modules in solutions, what they refer to are actually analytical tools and processes rather than information, that is, codified knowledge. We thus consider the features of knowledge modules as codified, tacit and explicit. Since knowledge embodied in physical products is related to product features, this characteristic is not included in this research.

\subsubsection{Platform openness}

As previously mentioned, a digital platform consists of different subsystems, where their openness acts as an architectural feature, influencing a solution provider's control over its solution networks. In the platform literature, platform openness, as a governance-related concept, represents the trade-off between maintaining and relinquishing control over a platform and its constituent parts at the ecosystem level, including other organizations. Platform openness refers to "the easing of restrictions on the use, development and commercialization of a technology" (Boudreau, 2010, p.1851). Opening a platform to third parties can enhance the diversity of complementors and how their innovations contribute to the platform (Gawer, 2014), but relinquishing some control to third-parties may also lead to low efficiency, quality uncertainty and the loss of integrity (Boudreau, 2010, 2012). A firm can gain coordination and governance benefits by carefully designing and managing the openness of subsystems (Thomas et al., 2014).

This study argues that platform openness needs to be considered at both a solution level and an interfirm level, as a solution provider may be able to balance platform openness and control in their platform by modulating across these two levels. For example, a solution provider can open a module to complementors by involving them in manufacturing a component (solution level) while closing a digital subsystem by cutting information flows between complementors and customers in a digital infrastructure to gain control benefits (interfirm level). At an interfirm level, this paper follows West \& O'Mahony (2008) high-level conceptualization of platform openness to capture the two distinct subdimensions of transparency and accessibility, seen as a continuum rather than a dichotomy of purely closed and purely open (West, 2003). The concept of transparency refers to whether a customer understands how the module is created or whether a provider understands how the module is distributed and communicates with customers without restrictions. For example, while high transparency indicates that customers can communicate with module providers directly, low transparency indicates that customers have limited or no direct communication with module providers, and vice versa. Therefore, transparency points to the level of information exchange among relevant parties. The concept of accessibility refers to whether a customer can access the module without restrictions and whether a provider can distribute the module without restrictions. For example, while high accessibility means that customers can access the module offered by module providers directly, low accessibility means that customers can do that only through complying with restrictions set by solution providers, and vice versa. Therefore, this concept highlights the levels of restrictions imposed on interactions between customers and module providers. 
At the solution level, we adapt Jacobides, Knudsen, and Augier (2006)'s definition and perceive platform openness as the level of value chain involvement of third-party complementors in different modules. Quite simply, a solution provider can involve a third party to offer a module jointly, or it can offer this module itself without involving anther third party. This construct can capture how a solution provider exerts control over different subsystems by adjusting openness from different dimensions.

Finally, according to Thomas et al. (2014), we define control benefits here as coordination and governance benefits for solution providers through managing the openness. A solution provider wants to control the solution process so that it can ensure quality and efficiency. However, the diversity of modules on a platform may prevent it from using unified coordination mechanisms, since the module features of products, services and knowledge imply that provisions of these modules require different forms of interfirm coordination. For example, tacit knowledge transfer requires close interactions between firms while explicit knowledge transfer requires less collaboration. Since platform openness influences interfirm coordination through affecting information exchange and interactions, solution providers can set different levels of platform openness to control interfirm coordination according to the module features. In doing so, solution providers can reap different control - that is, governance and coordination - benefits.

To summarise this brief discussion, our research draws simultaneously on solution business and IS research to conceptualize a platform approach from a two-level perspective, that is, a solution level and an interfirm level. We suggest that both literatures complement each other well; where B2B marketing studies on solution businesses have mainly focused on the interfirm coordination level, the IS literature has taken an architectural perspective to explore platform openness design. At a solution level, a modular structure allows the firm to develop a wide range of customized solutions consisting of easily interchanged modules. These modules include service modules, product modules and knowledge modules. They have different features that require different interfirm coordination. At an interfirm level, a digital platform with a modular structure consists of subsystems of different business partners with different resources and capabilities. Platform openness can be designed across both levels and in different dimensions, that is, transparency, accessibility and involvement. Since these dimensions indicate the restrictions on information exchange and interactions among firms on a platform, different levels of openness influence interfirm coordination. Since modules with different features requires different interfirm coordination, they influence the settings of platform openness, with which solution providers have different coordination and governance benefits. Thus, setting platform openness differently according to different module features can lead to different control benefits for solution providers. Fig. 1 summarizes and illustrates our theoretical framework.

\section{Methodology}

\subsection{Case research and selection}

Case research enables us to gain a deeper understanding of architectural features in a platform context. A multiple case study design was adopted to explore the links between the different concepts of our theoretical framework by comparing and contrasting deep case insights (Yin, 2003). Three solution providers with digital platforms headquartered in China have been selected as cases for this study. The Chinese industrial context has become increasingly important in terms of solution business (e.g. Powers, Sheng, \& Li, 2016; Raja \& Frandsen, 2017; Zhang, Zhao, Voss, \& Zhu, 2016). The suitability of these three platforms for this research follows from their modular characteristics at the solution level and the interfirm level. At the solution level, the modular structure of their offerings enables them to recombine a large variety of products, services and knowledge into customized solution packages. At an interfirm level, different business partners involved in the delivery of the solution are connected and coordinated through digital infrastructures and organizational processes in the platforms. These firms also represent typical business models for the digital service platform phenomenon, with the industrial difference increasing the study's external validity (Yin, 2003).

One platform (AL) is in the lighting facility industry and the other two (HQ and CK) are in the information and communication technology (ICT) industry. AL offers one-stop solutions for lighting plans to key buyers such as property developers. It helps them through different stages of the solutions, from overall planning, product designs, and accreditation services to the lighting plan implementation. Thus, the firm needs to coordinate different business partners to deliver its solutions efficiently, and its solutions are always customized to adapt to different customer needs. AL maintains a digital platform to coordinate the transactions among its business partners' offerings, such as components, products, designers' services, and standard testing agencies' services.

Our two case companies in the ICT industry, CK and HQ, offer endto-end solutions to engineering companies for their new product development. They provide a variety of solution offerings to help their client companies from product design, product development and sample product manufacturing to industrial services such as standard testing and design optimization. They resell components such as motherboards, printed circuit boards (PCBs), different electronic components and tools from suppliers in their digital platforms. They also offer component assembling services to these engineering firms. While CK offers data analytics and design optimization to customers, HQ offers standard testing services. In both platforms, customers can acquire knowledge and gain advice from experts in the online communities. Transactions are managed through payment services and information transfer devices. Table 2 presents the main business features of all three platforms.

\subsection{Data collection and research method}

Based on the criteria mentioned in section 3.1 and a directory of digital platforms relevant to B2B solutions, several suitable companies were contacted by phone or via email to explore their willingness to take part in the research. The three companies described in Table 2 were willing to participate. The units of analysis are at the solution level. In each platform, a top selling solution was selected with the help of directors. The main data collection methods involved 25 semistructured interviews with participants related to different modules in the solution as per Table 3. To gather comprehensive information, interview participants were chosen to cover different activities in different modules and at different levels related to the solution. Prior to each interview, the respondents were informed of the objectives of the study and the interviews and how confidentiality would be ensured. In addition, informed consent was obtained in writing. To obtain information about customer perceptions, interviews were conducted with key customers selected by the organizations. Interviewees were first asked to describe their business activities in the solution context. Then questions focused on the modules involved, the interactions among modules, and interdependency among module providers, customers, and the solution providers. Interviews were audio-taped, transcribed verbatim and translated for analysis by the first author who is fully bilingual; the transcripts were then sent back to the interviewees to verify correctness and accuracy (Johnston, Leach, \& Liu, 1999).

According to Meredith (1998), multiple methods and tools for data collection assist in understanding complex, real-life phenomena. The combination of data from different sources and methods offers data source triangulation (Gibbert, Ruigrok, \& Wicki, 2008). Therefore, to supplement interview data, internal firm documents about stakeholders, for instance module providers, were examined and analysed. These documents include process descriptions, product books, 
Table 2

Case companies, main business and modules.

\begin{tabular}{|c|c|c|}
\hline Companies & Main business & Modules \\
\hline HQ & $\begin{array}{l}\text { As a PCB manufacturer originally, HQ relies on its PCB business to resell other electronic components in } \\
\text { their digital platforms. It has an online community where it facilitates sharing industrial knowledge. }\end{array}$ & $\begin{array}{l}\text { Product modules } \\
\text { - PCBs } \\
\text { - core electronic components (e.g. CPUs) } \\
\text { - peripheral electronic components (e.g. capacitors) } \\
\text { Service modules } \\
\text { - product support services, } \\
\text { - standard testing services, } \\
\text { - customer support services, } \\
\text { Knowledge modules } \\
\text { - consultation, } \\
\text { - training videos } \\
\text { - standard designs and design rules }\end{array}$ \\
\hline CK & $\begin{array}{l}\text { CK is an industrial service company. It offers PCB manufacturing with other business partners and } \\
\text { electronic components reselling. It also offers engineering design optimization based on the partnerships } \\
\text { with leading databases. It has an online community where it facilitates sharing industrial knowledge. }\end{array}$ & $\begin{array}{l}\text { Product modules } \\
\text { - PCBs } \\
\text { - core electronic components } \\
\text { (e.g. CPUs) } \\
\text { - peripheral electronic components (e.g. capacitors) } \\
\text { Service modules } \\
\text { - customer support services, } \\
\text { Knowledge modules } \\
\text { - training videos } \\
\text { - design optimization, } \\
\text { - standard designs and design rules } \\
\text { - consultation, } \\
\text { - data about trends and component performance }\end{array}$ \\
\hline $\mathrm{AL}$ & $\begin{array}{l}\text { AL is an industrial service company in the LED industry. } \\
\text { It offers solutions to property developers to design and implement lighting plans. It coordinates component } \\
\text { suppliers, designers, engineering firms, standard testing firms to offer these solutions, with its digital } \\
\text { platform supporting the processes. }\end{array}$ & $\begin{array}{l}\text { Product modules } \\
\text { - Core product components (e.g. lamp beads) } \\
\text { - Peripheral product components (e.g. customized } \\
\text { lighting facilities) } \\
\text { Service modules } \\
\text { - customer support services } \\
\text { - standard testing services, } \\
\text { - financial services, } \\
\text { - implementing services } \\
\text { - integrating different service modules and product } \\
\text { modules in a solution, } \\
\text { Knowledge modules }\end{array}$ \\
\hline
\end{tabular}

handbooks, and quality management procedures. Archival records such as meeting notes, records on client interactions, customer feedback and contract templates were also examined, as were documents about rules and regulations related to the event and implemented by the platforms. An analysis of the pertinent information systems in each firm was also conducted.

Thematic analysis was applied to all data gathered in order to generate an in-depth analysis of current processes (Lee, 1999; Miles \& Huberman, 1994). A systematic data reduction process was followed, which consisted of the following steps: reading of transcripts, document summaries and observation notes, segmentation of sentences and phrases, codification of text segments, generation of themes and categories, and identification of relationships (Saldaña, 2015). Since a list of preliminary codes can assist researchers in integrating concepts that were studied in extant literature, segmentation and coding began from an initial deductive code list to identify concepts at different levels, which was developed based on the theoretical concepts emanating from the literature review and from our theoretical framework presented in section 2. When reviewing the data, inductive codes were constructed and used to complement the theory-driven codes during data analysis (see Appendix 1 for further information). After the initial coding process, a systematic analysis was conducted across all forms of data to explore the mechanisms that are used to manage solutions. Assessment of platform openness levels was done based on the interviews, observation and documents. High transparency means that there is no restriction on understanding how to create or distribute a module from either side. High accessibility means that there is no restriction for customers in accessing the module or for suppliers to distribute the module. Low transparency or accessibility is defined as closure, that is, participants cannot know how to create or distribute a module by themselves, or they cannot access or distribute the module. If there were some restrictions in these two dimensions, they are identified as medium level of openness. For validation, findings were sent back to key informants who found the findings to be generally valid and suggested minor modifications only. Following Yin (2003), both withincase analyses and cross-case analysis were conducted to compare and contrast the processes of solution delivery, which will be presented in the following section.

\section{Findings}

The aim of this research was to explore how a focal firm manages 
Table 3

Interviewees and job roles.

\begin{tabular}{|c|c|c|c|}
\hline Company & Industry & $\begin{array}{l}\text { Number of } \\
\text { Employees }\end{array}$ & $\begin{array}{l}\text { Respondent job title and numbers of } \\
\text { interviews per respondent }\end{array}$ \\
\hline HQ & ICT & 340 & $\begin{array}{l}7 \text { interviews: } \\
\text { - Chief Operations Officer (1), } \\
\text { - CEO (1), } \\
\text { - Online Community Manager (1) } \\
\text { - Supply Chain Manager (1), } \\
\text { - PCB Manager (1), } \\
\text { - Customers (2). }\end{array}$ \\
\hline CK & ICT & 93 & $\begin{array}{l}9 \text { interviews } \\
\text { - Operations Director (2) } \\
\text { - PCB and Supply Chain Manager (2) } \\
\text { - Operations Manager (1), } \\
\text { - Online Community Manager (1) } \\
\text { - Customers (3) }\end{array}$ \\
\hline AL & LED & 115 & $\begin{array}{l}9 \text { interviews: } \\
\text { - Operations Director (3) } \\
\text { - Operations Manager and Operations } \\
\text { - Director (1), } \\
\text { - Project Manager (1) } \\
\text { - General Secretary of Design } \\
\text { - Academy (1), } \\
\text { - Supply Chain Supervisors (1), } \\
\text { - Key Account Manager (2). }\end{array}$ \\
\hline
\end{tabular}

platform openness through various module features. In addition, we investigate how openness and module features interact at different levels, that is, solution and interfirm levels, for control benefits. The findings in this study reveal that features of different modules influence platform openness differently. As mentioned previously, we distinguish three different module types: service modules, product modules, and knowledge modules. The features of product modules (core or peripheral), service modules (relationship intensity and customization), and knowledge modules (explicit, tacit and codified) influence the levels of platform openness in different ways. By setting platform openness of different subsystems accordingly, solution providers gain different control benefits, such as ensuring module quality, increasing offering variety, reducing dependence from module providers and adjusting supply uncertainty. The following sections discuss the findings in detail.

\subsection{Product modules}

The theoretical framework depicts module features as consisting of product modules being core or peripheral. The level of platform openness is strongly influenced by these product module features. To recall, a core component can influence a large proportion of other components (Gawer \& Cusumano, 2008) while other peripheral components can increase the variety of the offerings (Baldwin \& Woodard, 2008). Table 4 summarizes the levels of platform openness for product modules and the resultant control benefits. As for core product modules, the cases show that platform openness is relatively low so that solution providers reduce the dependence on core component suppliers and adjust supply uncertainty.

A solution provider controls the provision of core product modules with a closed system since the selection of core product modules influences the selection of other product modules as well as the overall performance of a solution. The solution providers rely on core product module suppliers for providing these modules. However, they reduce dependence on these suppliers with a closed system to increase the control level. For example, only selected business partners are involved in creating or distributing core product modules in CK and HQ, and AL even closes this distribution and resells them itself after testing product standards for quality assurance. Even though HQ and CK carefully

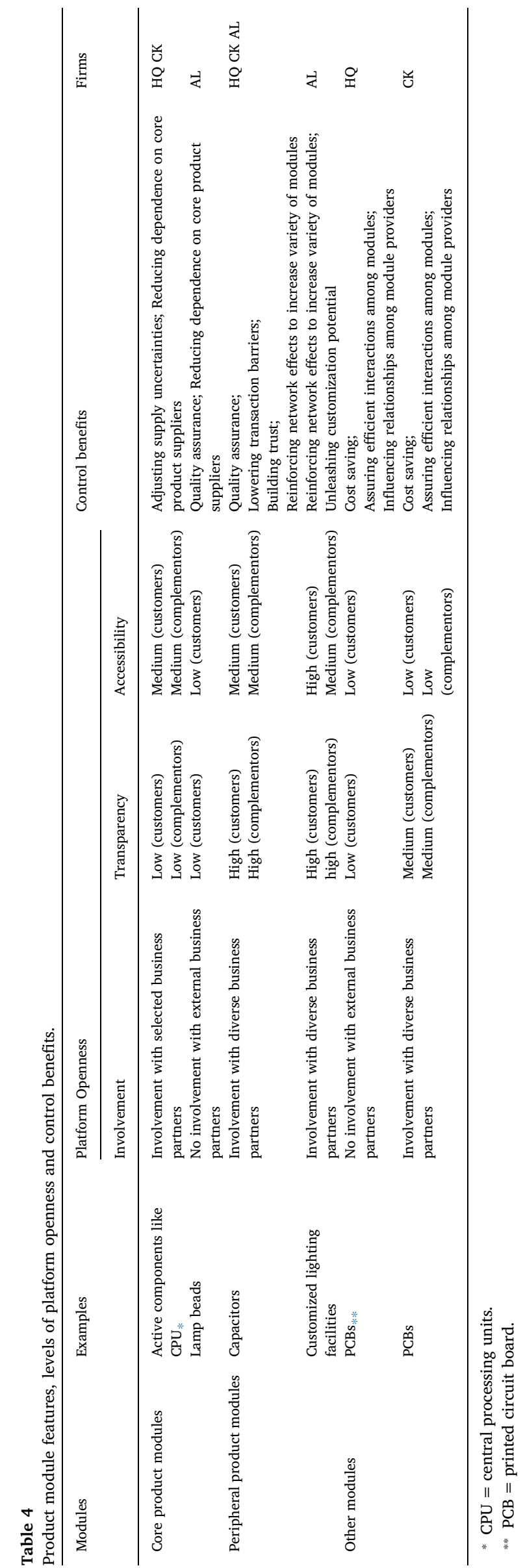


select these business partners, transparency in the system is very low. In doing so, CK and HQ keep suppliers and customers from gaining any information about changes in distribution channels. By withholding this information, the solution providers can change core product module suppliers to stabilize core module provision without informing customers and suppliers. AL also features low transparency in the selection of core products. Customers and suppliers all depend on their databases or internal specialists' advice for core product matching. This is to reduce dependence on the relationships among core product module suppliers and stabilize their supplies, as the following quote illustrates:

"If supplier IR is cheaper than supplier VQ or VQ has some uncertainties in their supplies, to avoid bad customer experience, we will purchase IR for our customers. We know that they belong to the same manufacturer, so we are sure that these components are the same. Only the suppliers are different......In addition, what we need to manage is our relationships with the suppliers. If our purchases from the suppliers are stable, there will be some inertia. They won't help us with issues like after-sale services or tight supplies. They will let us handle these issues by ourselves." (Operations Manager, CK).

For peripheral product modules, transparency is relatively high in all three cases to generate network effects, thereby enhancing the variety of peripheral product modules to customize the overall solutions. This network effect also leads to increasing diversity of business partners that are involved in developing and distributing these product modules. However, accessibility is at a medium level from the supplier side since the solution providers increase entry barriers for suppliers to ensure the quality of their supplies.

In HQ and AL, suppliers of peripheral products have online shops in the platforms to promote their product modules, so there is high transparency about their suppliers and their products. AL also has an online webpage for customers to announce their purchase requirements for these products. When the director in AL was asked about the purpose of this platform design, he replied:

"Popularity,... This is our platform business model. Our platform needs to have popularity. If we have popularity, more and more customers will use our platform. Then it will attract more and more suppliers and products." (Operations Director, $A L$ ).

However, accessibility is at a medium level since HQ and AL apply qualification examination and standard testing for these suppliers for quality assurance. CK also used to allow suppliers of peripheral product modules to sell their products directly when customers need to select peripheral product modules in their solutions; it is noteworthy that CK closed this system due to failure in quality assurance resulting from a lack of cooperation with standard testing firms. The following quote illustrates the importance of recognized quality assurance:

"When a supplier joins our platform, we will cooperate with international standard testing companies to assess the supplier's performance and quality. When a customer makes an order, we will also test the product quality. (Operations Director, $A L)$ ".

Customers and suppliers are also required to use online communication tools and online payment tools to coordinate the transactions. Information flows and cash flows are monitored or controlled in the system.

"Yes, they (suppliers or customers) can control their cash flow through our payment tools. For example, customers may require that only a certain percentage of fee will be released to a supplier before product delivery. Or suppliers may require that full amount fees need to be released before product delivery... We are open to these requirements, but they (customers and suppliers) can communicate and coordinate themselves." (Operations Director, AL).

Thus, transaction barriers resulting from the virtual and impersonal nature of the online environment are lowered, and mutual trust between suppliers and customers is enhanced. Hence, high transparency and medium accessibility for peripheral product modules stimulate network effects and increase the variety of peripheral product modules while maintaining control over the interactions between customers and suppliers and the quality of the modules.

The data also reveal that both CK and HQ apply low platform openness to impose control over a product module that can strengthen their influence over their business networks. In both cases, this module is printed circuit boards (PCBs), around which a suite of solutions is provided, since the firms sell other components added onto PCBs. A good-quality PCB ensures effective interactions among product components, thereby ensuring the overall performance of a solution. Thus, customers are encouraged to follow CK's or HQ's instructions and replace those components for which the PCB serves as an installation base. If they follow this advice, customers purchase other product components from other suppliers based on CK or HQ's instructions, which allows CK and HQ to influence the relationships in their broader business networks. The reusability of the internal manufacturing capabilities also helps HQ to achieve economies of scope and thereby realizing cost saving effects. As the Chief Operations Officer in HQ commented:

"We found that no matter what our customers want they all need PCBs... and we have more than 20 years of experience and expertise in $P C B . . .$. now we can reduce their costs and increase their efficiency and accelerate products' go to market time." (Chief Operations Officer, HQ).

Therefore, for a product module that influences relationships in business networks, a solution provider typically imposes low platform openness. This leads to cost saving effects and assurance of overall performance of a solution. Table 4 summarizes our insights into core and peripheral produce modules.

\subsection{Service modules}

The theoretical framework depicts service module features as customized and relationship intensive or not. Our data reveal that for service modules requiring high customization and highly intensive relationships, openness is set at a medium level to balance the double aims of controlling quality and facilitating customer-provider interactions. Solution providers also involve diverse business partners in this process. For example, AL and HQ offer technical standard testing services with diverse business partners to customers:

"In a solution which requires us purchase all the products, we frequently cooperate with third-party testing firms to test the products etc, which requires involvement with diverse standard testing firms." (Operations Director, $A L)$.

However, customers are required to register accounts to contact and access the service providers. Transactions are also controlled by the online payment services provided by HQ and AL. Therefore, the accessibility is at a medium level. Customers normally do not have enough knowledge about different technical standards, and the online information provided is not enough for the customers to choose standards providers independently from their solution provider:

"We help them to readily find accreditation and certifications in the solution, because we are very knowledgeable about these organizations [providing testing services]" (Operations Director, $A L$ ).

HQ and AL have online help desks to help customers choose the appropriate technical standards. The technical standard testing services are highly customized as the solutions themselves are very customized and new product development is sometimes necessary in a solution. The standard testing services also vary according to target markets and product differences in the solutions. Diverse standard testing providers are involved. The online helpdesks facilitate efficient matching between service providers and customers, service offerings and customer 
requirements, thereby reducing the complexity resulting from modularity and diversity. In order to ensure quality, facilitate matching and control the relationship, transparency is at a medium level and, consequently, platform openness is not high. At the same time, it cannot be too low either: high levels of customization require frequent exchanges on technical standards between customers and providers, thereby leading to high relationship intensity, and low platform openness would hinder interactions. Therefore, to balance controlling service quality and relationships with facilitating interactions, platform openness is set at a medium level. Integrating services are also very customized and have high relationship intensity, since AL interacts with customers in combining and integrating suitable products and services according to different customer needs. However, due to its positioning in a solution, this service module has low platform openness, which will be further discussed in the final section.

For service modules that have low customization and low relationship intensity, such as customer support services, low openness level is imposed to control service quality and flows between customers and providers. For instance, all solution providers in our cases offer technical product samples for customers to experience the products before purchase. Documentation about these products is also provided. These materials and samples are obtained from suppliers and delivered to customers.

"We also cooperate with suppliers in sample delivery. We will showcase the sample information online, which is from more than 100 suppliers. This is free sample delivery, which allows customers to obtain samples easily. We will then transfer the customers' sample application information online to the suppliers. Suppliers will send out the samples to us, and we will help distribute these samples, thereby lowering suppliers' costs." (Operations Director, CK).

Since these services are standardized and feature low relationship intensity, platform openness is low so that the solution providers control material and information flows. While ensuring service quality, this also lowers the cost for both sides.

By contrast to the other firms, AL offers in-house integrating services, which feature high customization and high relationship intensity. These services help AL guide customer product selection and thereby influence the relationships in its networks:

"Customers' projects go through our platform, where we help them to find designers to offer designs, then they make decisions on which designers can get the projects. ...The role of our platform is to help them search designs, products, and implementers and integrate them into service packages." (Operations Director, $A L$ ).

While CK and HQ use PCBs as installation bases to influence customer product selection and ensuring the overall performance of the solutions, AL lacks these installation bases. Instead, they use integrating services, and accordingly, platform openness for this module is low. Transparency is also low; as other business partners are not involved in these services, AL can tightly control the information flow. Table 5 summarizes our findings for service modules.

\subsection{Knowledge modules}

The theoretical framework depicts knowledge module features as tacit, codified and explicit. To recall, knowledge is defined as the combination of information that leads to valuable insights, know-how and actionable guidance through adding expert opinion, understanding, accumulated learning and experience (Rowley, 2007). It is important to note that this paper focuses on knowledge in itself rather than knowledge transfer activities (as a type of services); the knowledge modules we consider in our cases are for instance consultation (know-how), standard designs and industry reports (valuable insights) and training videos (actionable guidance).

Tacit knowledge requires intensive interactions and trust to facilitate knowledge transfer, so when modules contain a high level of tacit knowledge platform openness is high. In their consultation module, for instance, $\mathrm{CK}$ and $\mathrm{HQ}$ involve different experts with diverse expertise in their online community for customer advice on solution development. Having high platform openness enhances customer-provider interactions and strengthens mutual trust, thereby facilitating knowledge sharing.

"This community offers participants new knowledge. I also browse their website to check whether there are some new comments written by opinion leaders. This offers me some insights about what is going on in the industry and some comments on certain technological issues." (Customer $S$, HQ).

High platform openness also increases the variety of the expertise, which in turn creates network effects, as the platform becomes an important forum for knowledge sharing with customers. However, accessibility is at a medium level for complementors since information about these experts is checked by the solution providers to enhance credibility and foster trust in these experts:

"The more information there is, the more credible this participant is. The basics are email address, mobile phone number, ID card and his picture, all of which were examined by us to prove credibility. In terms of corporate information, business cards and badges were examined. In this profile, the projects he has finished and the posts he has contributed will be also shown, which could be used by other participants to evaluate his capability." (Community Manager, CK).

This information is shown in online profiles, which help customers make better judgements. Since customers consult with different experts in this online community at the same time, this information facilitates better matching between experts and customers and between technical know-how and customers' issues, thereby reducing the complexity resulting from diversity of expertise.

For codified knowledge, openness is maintained at a medium level so that solution providers control information sources and create dependence from both sides while facilitating knowledge sharing. For example, CK offers data about product component performance to customers so that customers improve their design and adjust their sourcing based on the data. However, a customer is required to register an account to gain access to the database. Customers do not know how a report about a product component is generated, and the database provider cannot communicate with customers directly either. Since codified knowledge does not require intensive interactions to transfer, CK controls the transfer process. Therefore, accessibility and transparency levels - and consequently platform openness - are at a medium level. CK also uses its internal resources to offer design optimization modules without involving other business partners. In doing so, CK protects its own resources and controls the module quality. Although customers access this module directly, transparency is low. Since this module helps CK influence customers' decisions on product selection, with low transparency CK exerts influence over the relationships among product suppliers and creates customer dependence.

Explicit knowledge generally does not require involvement with other parties, since these parties normally do not gain commercial value, as this quote illustrates:

"Generally speaking, it is very difficult for customers and experts to codevelop standard designs in the online community, since there is no commercial value for them. Solution providers (like us) will develop these standard designs, which will be modified if necessary for new usage." (Community Manager, CK).

These standard designs are offered as documents by the solution provider upon request, and customers modify these designs when they need new solutions. Accessibility is high while transparency is low, as the solution provider creates dependence of customers and other business partners through keeping the knowledge within their own 
Table 5

Service module features, levels of platform openness \& control benefits.

\begin{tabular}{|c|c|c|c|c|c|c|}
\hline \multirow[t]{2}{*}{ Service module Examples } & \multirow[t]{2}{*}{ Features } & \multicolumn{3}{|l|}{ Platform Openness } & \multirow[t]{2}{*}{ Control benefits } & \multirow[t]{2}{*}{ Firms } \\
\hline & & Involvement & Transparency & Accessibility & & \\
\hline Technical standards testing & $\begin{array}{l}\text { High } \\
\text { customization } \\
\text { High relationship } \\
\text { intensity }\end{array}$ & $\begin{array}{l}\text { Involvement with } \\
\text { diverse business } \\
\text { partners }\end{array}$ & $\begin{array}{l}\text { Medium (customers) } \\
\text { Medium } \\
\text { (complementors) }\end{array}$ & $\begin{array}{l}\text { Medium (customers) } \\
\text { Medium } \\
\text { (complementors) }\end{array}$ & $\begin{array}{l}\text { Facilitating customer- } \\
\text { provider interactions; } \\
\text { Controlling the relationships } \\
\text { among module providers; } \\
\text { Efficient matching }\end{array}$ & $\begin{array}{l}\mathrm{AL} \\
\mathrm{HQ}\end{array}$ \\
\hline Integrating services & $\begin{array}{l}\text { High } \\
\text { customization } \\
\text { High relationship } \\
\text { intensity }\end{array}$ & $\begin{array}{l}\text { No involvement with } \\
\text { other business } \\
\text { partners }\end{array}$ & Low (customers); & High (customers) & $\begin{array}{l}\text { Protecting internal resources; } \\
\text { Assuring solution quality; } \\
\text { Influencing the relationships } \\
\text { among module providers; } \\
\text { Efficient matching }\end{array}$ & $\mathrm{AL}$ \\
\hline $\begin{array}{l}\text { Customer support (sample delivery, } \\
\text { provision and update of technical } \\
\text { documentation help desk supports) }\end{array}$ & $\begin{array}{l}\text { Low customization } \\
\text { Low relationship } \\
\text { intensity }\end{array}$ & $\begin{array}{l}\text { Involvement with } \\
\text { selected business } \\
\text { partners }\end{array}$ & $\begin{array}{l}\text { Low (customers) } \\
\text { Low (complementors) }\end{array}$ & $\begin{array}{l}\text { Low (customers) } \\
\text { Low (complementors) }\end{array}$ & $\begin{array}{l}\text { Quality assurance; } \\
\text { Controlling information } \\
\text { flows and material flows } \\
\text { between providers and } \\
\text { customers }\end{array}$ & $\begin{array}{l}\mathrm{AL}, \mathrm{CK}, \\
\mathrm{HQ}\end{array}$ \\
\hline
\end{tabular}

firm. High accessibility in turn facilitates knowledge sharing. Table 6 illustrates this subsection's findings.

To summarise, different module features leads to different configurations of platform openness. We further aggregate these configurations according to different module features in Table 7 . By setting different levels of openness in these dimensions, solution providers have the combined benefits in controlling solution networks, which will be aggregated and discussed in the next section.

\section{Discussion}

Previous studies have recognized that module features can impact interfirm coordination (e.g. Brusoni \& Prencipe, 2001; Saccani et al., 2014; Valtakoski, 2017). The literature on platforms also suggests that platform openness can be used to influence interfirm coordination (e.g. Thomas et al., 2014). Combining these literatures and studying some of the suggested relationships empirically, this study set out to explore how solution providers leverage platform openness to control solution networks. We adopted an architectural lens focused on product, service and knowledge module features to analyse how platform openness is managed across these different module types to generate control benefits. In this section, we continue the structure adopted in the findings and organize our discussion around the three module types included in our theoretical framework as per Fig. 1.

As for product modules, the modularity literature implies that whether a product is core or peripheral influences interfirm coordination (e.g.Brusoni \& Prencipe, 2001; Schilling, 2000). For example, solution providers may tend to keep core modules in-house while outsourcing peripheral modules (Brusoni \& Prencipe, 2001; Schilling, 2000). Our research complements this insight by highlighting that rather than keeping core modules in-house, solution providers involve other business partners to draw on external resources to offer these modules. They also set low platform openness (low transparency and low accessibility) for core modules offered by external providers, for instance by limiting the interactions between customers and module providers. In doing so, they can change core product module suppliers to stabilize core module provision without informing customers and suppliers, reduce the dependence on these module providers and adjust supply uncertainty. In turn, peripheral modules can increase the variety of the offerings and available customization options (Baldwin \& Woodard, 2008). Accordingly, our research finds that solution providers set high transparency to generate network effects in order to increase the variety of peripheral modules offered by external providers for example, allowing them to open online shops and webpages to promote products. However, accessibility is at a medium level, which is exemplified by a range of entry barriers put in place to ensure module quality, such as qualification examination and standard testing for these suppliers to enter the platforms. Therefore, we put forward the following propositions in relation to core versus peripheral products:

P1. Platform openness is low for core product modules to reduce the dependence on core product module suppliers and adjust supply uncertainty.

P2a. For peripheral product modules, high-level transparency generates network effects to enhance peripheral product variety and supplier diversity for solution customization.

P2b. For peripheral product modules, medium-level accessibility increases supplier entry barriers for quality assurance.

As for service modules, Saccani et al. (2014) find that information exchange between customers and providers is limited in services with low relationship intensity and low customisation, while information exchange is at a significant level in services with high relationship intensity. Consistent with this finding, our study reveals that for service modules requiring high customization and highly intensive relationships, openness is set at a medium level. Since frequent information exchanges take place in these services modules, low transparency hinders information exchange, especially when customers try to match their needs with service modules. Low accessibility also hinders interactions when customers customize the services. However, high platform openness cannot ensure quality, so solution providers impose some restrictions on the process, such as requiring account registrations and use of online communication tools and online payment tools. Therefore, the openness is set at a medium level to balance quality and efficient matching with facilitating customer-provider interactions. For service modules with low customization and low relationship intensity, information exchange is limited (Saccani et al., 2014), and our research finds that a low openness level is imposed so that the solution providers can control material and information flows - for instance when obtaining materials and samples from suppliers and delivering them to customers. Therefore, we have the following propositions.

P3. For service modules with high customization and high relationship intensity, a medium level of openness helps balance quality assurance and efficient matching and facilitating customer-provider interactions.

P4. For service modules with low customization and low relationship intensity, low openness is imposed to control service quality and customer-provider flows.

As for knowledge modules, prior studies find that tacit knowledge transfer requires close interactions between the firms (Simonin, 1999), while codified knowledge only requires loose interactions. Consistent 
Table 7

A summary of module features and levels of platform openness.

\begin{tabular}{|c|c|}
\hline Module features & Platform openness \\
\hline Core product modules & $\begin{array}{l}\text { Low transparency } \\
\text { Low accessibility } \\
\text { Involvement with third } \\
\text { parties }\end{array}$ \\
\hline Peripheral product modules & $\begin{array}{l}\text { High transparency } \\
\text { Medium accessibility } \\
\text { Involvement with third } \\
\text { parties }\end{array}$ \\
\hline $\begin{array}{l}\text { Service modules with high customization and high } \\
\text { relationship intensity }\end{array}$ & $\begin{array}{l}\text { Medium transparency } \\
\text { Medium accessibility } \\
\text { Involvement with third } \\
\text { parties }\end{array}$ \\
\hline $\begin{array}{l}\text { Service modules with low customization and low } \\
\text { relationship intensity }\end{array}$ & $\begin{array}{l}\text { Low transparency } \\
\text { Low accessibility } \\
\text { Involvement with third } \\
\text { parties }\end{array}$ \\
\hline Tacit knowledge & $\begin{array}{l}\text { High transparency } \\
\text { High accessibility } \\
\text { Involvement with third } \\
\text { parties }\end{array}$ \\
\hline Codified knowledge & $\begin{array}{l}\text { Medium transparency } \\
\text { Medium accessibility } \\
\text { Involvement with third } \\
\text { parties }\end{array}$ \\
\hline Explicit knowledge & $\begin{array}{l}\text { Low transparency } \\
\text { High accessibility } \\
\text { No involvement }\end{array}$ \\
\hline $\begin{array}{l}\text { A module that can influence customers' selection of } \\
\text { other modules }\end{array}$ & $\begin{array}{l}\text { Low transparency } \\
\text { Low accessibility } \\
\text { No involvement }\end{array}$ \\
\hline
\end{tabular}

with this, in order to build trust to transfer tacit knowledge, solution providers in our cases set high platform openness on this module, facilitating close supplier-customer interactions for example through online open expert communities. As for codified knowledge, since it only requires loose interactions, our solution providers impose a medium level of platform openness to control the transfer process. For example, they require customers to register accounts to gain access and limit direct communications between customers and data providers. As such, solution providers can control information sources and create dependence from both sides while facilitating knowledge sharing. By involving external providers, they also draw on external resources to offer the modules. Explicit knowledge in turn can be transferred in standardized, commonly understood forms and therefore requires less collaboration (Valtakoski, 2017). In order to keep this knowledge within their own firms and prevent its leakage to suppliers, solution providers do not involve other business partners and set low transparency for these modules. However, they maintain high accessibility for these modules so as to facilitate knowledge sharing. For example, standard designs are kept internally but are offered to customers if requested. In doing so, they create dependence from customers and business partners while facilitating knowledge sharing. We thus propose:

P5. For tacit knowledge, platform openness is high to build trust to transfer knowledge and enhance the variety of expertise.

P6. For codified knowledge, medium openness enables solution providers to control information sources and create dependence while facilitating knowledge sharing.

P7 For explicit knowledge, while low transparency can create dependence from customers and business partners, high accessibility can facilitate knowledge sharing.

If we take the findings of the previous three sections in the round, we can also make a general observation about how module features influence platform openness, which is independent of product, service 


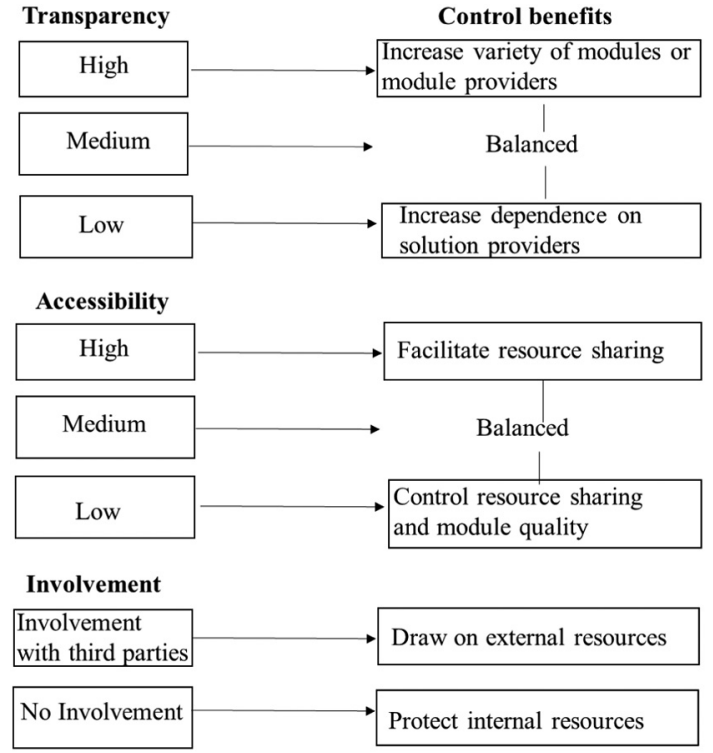

Fig. 2. Platform openness and control benefits.

and knowledge features. All three cases reveal that if the module can influence customers' selection of other modules, such as CK's design optimization, HQ's PCB module and AL's integrating service, solution providers use low platform openness to control the modules, thereby strengthening its influence over relationships in the networks. Therefore, we have the following final proposition:

P8. If a module can influence customers' selection of other modules, the solution providers close the subsystems to increase its network influence.

Through analysing the relationships between platform openness and control benefits across modules, we further summarise the general mechanisms on setting platform openness to have different control benefits, as Fig. 2 depicts. While high transparency increases the variety of modules or module providers, low transparency increases the dependence on solution providers. While high accessibility facilitates resource sharing, low accessibility controls resource sharing process and module quality. Solution providers balance the effects on two sides if transparency or accessibility is at a medium level. Solution providers involve other business partners to offer a module jointly to draw on external resources, while they have no involvement with other business partners in order to protect their internal resources. As mentioned previously, module features require certain levels of information exchange and interactions, which leads to the basic required levels of platform openness. After fulfilling these basic requirements, solution providers tend to manage platform openness to strengthen their control, such as increasing dependence on themselves and controlling resource sharing and module quality. For example, for a service with high customization and relationship intensity, a solution provider cannot use low transparency and low accessibility, since they constrain interactions and information exchange. So, it uses medium transparency and accessibility to enable interactions and information exchange. By doing so, it controls the sharing process and quality while facilitating resource sharing.

\section{Theoretical implications}

Based on the findings discussed above, this study makes the following theoretical contributions to the solution business literature. Firstly, this study offers insights into the heterogeneity of modules and its impact on network orchestration. It conceptualizes a solution as consisting of service modules, product modules and knowledge modules with different and pertinent features, while previous research only focuses on service-product bundles (Bask et al., 2010; Evanschitzky, Wangenheim, \& Woisetschläger, 2011; Pekkarinen \& Ulkuniemi, 2008) or considers a solution generally as a bundle of knowledge components (Valtakoski, 2017). While previous research has discussed using a modular structure to orchestrate business networks (Bask et al., 2010; Salonen et al., 2018), this study not only confirms the important role of a carefully designed modular structure in this process but also reveals the differential impacts different module features have on interfirm coordination in a digital platform context.

At an interfirm level, this study contributes to the B2B marketing literature by providing deep insights into the roles of digital platforms in orchestrating networks. By studying platform openness, this research offers important suggestions on realizing Eloranta and Turunen's (2016) network orchestration mechanisms from an architectural perspective. Solution providers can set high levels of openness to create network effects to extend the orchestrator's reach in complex networks. High platform openness can also build mutual trust, strengthen relational processes and create social embeddedness in the networks. Medium levels of openness can offer solution providers opportunities in efficiently matching service providers and customers by forming combinations of offerings and business partners in a diverse network. Low platform openness can reduce dependence on core suppliers and help adjust supply uncertainties, thereby supporting multiple network ties.

Furthermore, our study reconceptualizes platforms in solution networks from a two-level perspective, that is, solution level and interfirm level, and it deepens our understanding of how platform openness interacts with modular structure at these two levels to create control benefits. While recent research has acknowledged the complementary roles of both a modular solution structure and digital technologies in a platform in orchestrating internal units to generate and reconfigure modules (Cenamor et al., 2017), our two-level conceptualization extends this view to an external network perspective. Our findings explain how controlling certain types of modules with digital platform architecture can benefit orchestrating complex solution networks. Recent studies have pointed out that a platform can offer a structure for B2B network orchestration (Eloranta \& Turunen, 2016; Perks et al., 2017). They show that solution providers maintain only enough structure to prevent opportunism and retain control when reaching the limits of reducing complexity (Eloranta \& Turunen, 2016). By contrast, this study puts forward a contingent and more differentiated framework and finds that the control level depends on the features of the modules. By setting platform openness levels according to different features of modules at a solution level, the solution providers can have different control benefits at a network level, such as reducing dependence from module providers, adjusting supply uncertainty and efficient matching. The platform literature has suggested that lead firms should determine the overall design and basic technical architecture for a network-centric platform (Gawer \& Cusumano, 2014; Nambisan \& Sawhney, 2011). This study delves into the details of how lead firms can exploit architectural or structural features at both the solution level and interfirm level, and to influence and orchestrate networks more effectively.

Finally, we also contribute to the platform literature by offering a more comprehensive conceptualization of platform openness. By combining IS and networks literatures, we have reconceptualized platform openness as a multi-level and two-sided construct, while prior research views platform openness at a single level and from a single perspective (Jacobides et al., 2006; West \& O'Mahony (2008)). Our conceptualization allows further insights about how different participants in a platform interact with each other for value co-creation. It also crystallizes the impacts, risks and benefits of platform openness on platform control. We hope that these insights will form an important basis for future studies on B2B platforms.

\section{Managerial implications}

Our conceptualizations have implications that are highly relevant 
for network and platform managers. For instance, while we acknowledge that service modules also tend to be knowledge rich, we would encourage managers to more formally model knowledge contributions as part of their solution structure. Since knowledge especially around data analytics is becoming increasingly important in the digital world, customer solution providers need to explicitly formalize knowledge as modules in their solutions and understand how to manage these knowledge modules in their digital platforms. A shift from knowledge transfer activities to knowledge as a module itself can lead to better knowledge management and knowledge application in solution business where knowledge intensiveness increases due to digitization.

Additionally, our cases reveal that the design of a modular solution structure and a platform architecture that supports its implementation is not simple. As we showed, platform architecture can serve to institute control points for customer solution providers to exert control over large and diverse networks. For this, managers need to carefully examine and combine the features of different modules in their solutions in the design of their digital platforms to control their solution deliveries efficiently and at low cost. Solution providers can set different platform openness levels according to different module features, such as service, product, or knowledge. Resultant control benefits range from ensuring module quality, increasing offering variety, reducing dependence from module providers and facilitating resource sharing. Since engaging customers and drawing resources from external partners are crucial tasks in solution businesses, solution providers can leverage platform openness in their digital platforms to manage triadic interactions between "customer-solution provider-business partner" more efficiently but with relatively small amounts of effort. More generally, fully modelling a platform's architecture, as explained in this study, will give managers a better choice menu of balancing platform openness and control in their digital networks.

Finally, in many digital contexts, an increasing variety of modules and a large number of diverse business partners contribute to the complexity of a solution business. Clearly, neither offering all modules in-house nor outsourcing them to external business partners would be an effective and efficient approach. Therefore, solution providers need to identify those modules that can help them most beneficially influence customer selection of other modules and the relationships among module providers. They can offer these modules with their own resources and lower the transparency, thereby enhancing their influence over their solution networks. By doing so, they can also focus their resources on the most influential modules while ensuring efficient delivery of a solution.

\section{Limitations and future directions}

This research provides detailed insight into how solution providers may design platform openness of a digital platform through carefully managing different module features in order to exert control over their solution networks. As with any research, this study has some limitations. Firstly, this study has benefitted from unique access to three case firms in two different industries. While the industrial differences between our case companies enhance our findings' external validity, we only consider two industries, the LED and ICT industries. Other industrial backgrounds may lead to slightly different findings. Secondly, data collection was conducted in one country (China) only; although the Chinese B2B context (in particular in its digital form) is becoming increasingly important globally, this specific cultural background may have influenced our findings.

Finally, we would encourage future research to test our propositions through quantitative methods such as modelling. This would involve developing measures for platform openness and different module features in solution business context and test the proposed relationships. Based on our observations of several platforms across levels in this study, we would encourage future research to further investigate architectural innovation in services, including the external determinants on architectural control and the changing dynamics of the platform approach. An extension of this research may also consider modularity and platform issues in related contexts such as customer-sales interfaces in complex solution sales (e.g. Hohenschwert \& Geiger, 2015).

\section{Conclusion}

This study combines two highly topical business-to-business phenomena: on the one hand, managing a solution business often relies on network orchestration, and on the other adopting a platform approach has become increasingly important due to digitization and the increasing complexity of solution networks. The hybrid combination of services, products and knowledge in digital platforms and the complexity of solution networks require managers to find effective network control at low cost. Through the lens of the architecture of digital platforms, this study puts forwards a contingency framework in controlling solution networks. Although limited to a 'small N' multiple case study design, this research offers a strong rationale for careful platform design and control in the solution business context. It contributes to our understanding of the roles of digital platforms in this context. It also facilitates future research on digital platforms in the rapidly changing universe of digitization in the solution business.

\section{Appendix A}

Codes:

\begin{tabular}{|c|c|c|c|}
\hline Theoretical background & Topics & Deductive codes & Inductive codes \\
\hline \multirow[t]{3}{*}{$\begin{array}{l}\text { Platform openness (Jacobides et al., 2006; West \& } \\
\text { O'Mahony (2008)) }\end{array}$} & Transparency & $\begin{array}{l}\text { Information about module development } \\
\text { Information about module distribution } \\
\text { Information about customers } \\
\text { Direct communication between custo- } \\
\text { mers and providers }\end{array}$ & Availability of online communication tool in the platform \\
\hline & Accessibility & $\begin{array}{l}\text { Free access to modules } \\
\text { Modules distributed without any re- } \\
\text { strictions }\end{array}$ & $\begin{array}{l}\text { Registration required } \\
\text { Examining qualifications of module providers } \\
\text { Requirements in using channels provided by solution provi- } \\
\text { ders }\end{array}$ \\
\hline & Involvement & $\begin{array}{l}\text { Module distributed by the solution pro- } \\
\text { vider } \\
\text { Module distributed by the third-parties }\end{array}$ & \\
\hline Service modules (Saccani et al., 2014) & $\begin{array}{l}\text { Service module fea- } \\
\text { tures }\end{array}$ & $\begin{array}{l}\text { High customization } \\
\text { Low customization } \\
\text { High relationship intensity } \\
\text { Low relationship intensity }\end{array}$ & $\begin{array}{l}\text { Frequent exchanges between customers and suppliers } \\
\text { No direct exchange between customer and supplier }\end{array}$ \\
\hline
\end{tabular}


Product modules (Baldwin \& Woodard, 2008; Gawer Product module \& Cusumano, 2008).

Knowledge modules (Valtakoski, 2017) features

Knowledge module features
Core product components Peripheral product components

Tacit knowledge Codified knowledge Explicit knowledge
Product components influencing many other components Products that don't influence many other components but increase variety of solutions Technical know-how

Data analysis, industry reports

\section{Appendix B}

Interview protocol.

Solution providers:

1. What type of solution does your company offer?

2. Please describe various module types in the solutions provided by your platform

3. What providers are involved in these modules? What are their roles and functions?

4. Please describe how customers and module providers interact on your platforms

5. For different modules, how did your firm design the platform to manage the interactions between customers and module providers? Did your firm use different instruments, tools and mechanisms? Why?

6. What are the key issues that your firm needs to manage during solution delivery? Did your platform design influence your firm's management of these issues? Why?

\section{Customers:}

1. Please describe your company's main business and industry

2. Why did you want to buy a solution from this firm? What are its advantages?

3. Please describe the offerings your firm have bought from the solution provider.

4. Please describe the process about how your firm bought and received the offerings from the solution provider.

5. How did your firm interact with different module providers on the digital platforms?

6. How do you think about their platform design? How did the design influence the solution process?

7. What were the most satisfying aspects of this process? Why?

8. Did you have any issues in this process? How were these issues solved in the end?

\section{References}

Aarikka-Stenroos, L., \& Jaakkola, E. (2012). Value co-creation in knowledge intensive business services: A dyadic perspective on the joint problem solving process. Industrial Marketing Management, 41(1), 15-26.

Ardolino, M., Rapaccini, M., Saccani, N., Gaiardelli, P., Crespi, G., \& Ruggeri, C. (2018). The role of digital technologies for the service transformation of industrial companies. International Journal of Production Research, 56(6), 2116-2132.

Baldwin, C., \& Clark, K. (1997). Managing in an age of modularity. Harvard Business Review, 75(5), 84-93.

Baldwin, C., \& Clark, K. (2000). Design rules: The power of modularity. Vol. 1. MIT press.

Baldwin, C., \& Woodard, C. (2008). The architecture of platforms: A unified view. In A. Gawer (Ed.). Platforms, markets and innovation (pp. 19-44). Cheltenham, UK and Northampton, MA: Edward Elgar.

Bask, A., Lipponen, M., Rajahonka, M., \& Tinnilä, M. (2010). The concept of modularity: Diffusion from manufacturing to service production. Journal of Manufacturing Technology Management, 21(3), 355-375.

Boudreau, K. (2010). Open platform strategies and innovation: Granting access vs. devolving control. Management Science, 56(10), 1849-1872.

Boudreau, K. (2012). Let a thousand flowers bloom? An early look at large numbers of software app developers and patterns of innovation. Organization Science, 23(5), $1409-1427$.

Brax, S., \& Jonsson, K. (2009). Developing integrated solution offerings for remote diagnostics: A comparative case study of two manufacturers. International Journal of Operations \& Production Management, 29(5), 539-560.

Brusoni, S., \& Prencipe, A. (2001). Managing knowledge in loosely coupled networks: Exploring the links between product and knowledge dynamics. Journal of Management Studies, 38(7), 1019-1035.

Cenamor, J., Sjödin, D., \& Parida, V. (2017), Adopting a platform approach in servitization: Leveraging the value of digitalization. International Journal of Production Economics, 192, 54-65.

Choi, T., \& Krause, D. (2006). The supply base and its complexity: Implications for transaction costs, risks, responsiveness, and innovation. Journal of Operation Management, 24(5), 637-652.

Coreynen, W., Matthyssens, P., \& Van Bockhaven, W. (2017). Boosting servitization through digitization: Pathways and dynamic resource configurations for manufacturers. Industrial Marketing Management, 60, 42-53.

Cusumano, M., \& Gawer, A. (2002). The elements of platform leadership. MIT Sloan Management Review, 43(3), 51.

Davies, A., Brady, T., \& Hobday, M. (2006). Charting a path toward integrated solutions. Vol. 47(3), MIT Sloan Management Review39.
Davies, A., Brady, T., \& Hobday, M. (2007). Organizing for solutions: Systems seller vs. systems integrator. Industrial Marketing Management, 36(2), 183-193.

Eloranta, V., \& Turunen, T. (2016). Platforms in service-driven manufacturing: Leveraging complexity by connecting, sharing, and integrating. Industrial Marketing Management, 55, 178-186.

Evanschitzky, H., Wangenheim, F., \& Woisetschläger, D. (2011). Service \& solution innovation: Overview and research agenda. Industrial Marketing Management, 40(5), 657.

Frankenberger, K., Weiblen, T., \& Gassmann, O. (2013). Network configuration, customer centricity, and performance of open business models: A solution provider perspective. Industrial Marketing Management, 42(5), 671-682.

Gawer, A. (2014). Bridging differing perspectives on technological platforms: Toward an integrative framework. Research Policy, 43(7), 1239-1249.

Gawer, A., \& Cusumano, M. (2008). How companies become solution providers. MIT Sloan Management Review, 49(2), 28.

Gawer, A., \& Cusumano, M. (2014). Industry platforms and ecosystem innovation. Journal of Product Innovation Management, 31(3), 417-433.

Gebauer, H., Paiola, M., \& Saccani, N. (2013). Characterizing service networks for moving from products to solutions. Industrial Marketing Management, 42(1), 31-46.

Gibbert, M., Ruigrok, W., \& Wicki, B. (2008). What passes as a rigorous case study? Strategic Management Journal, 29(13), 1465-1474.

Grönroos, C. (1990). Service management: A management focus for service competition. International Journal of Service Industry Management, 1(1), 6-14.

Henfridsson, O., \& Bygstad, B. (2013). The generative mechanisms of digital infrastructure evolution. MIS Quarterly, 37(3), 907-931.

Hobday, M., Davies, A., \& Prencipe, A. (2005). Systems integration: A core capability of the modern corporation. Industrial and Corporate Change, 14(6), 1109-1143.

Hohenschwert, L., \& Geiger, S. (2015). Interpersonal influence strategies in complex B2B sales and the socio-cognitive construction of relationship value. Industrial Marketing Management, 49, 139-150.

Jacobides, M., Knudsen, T., \& Augier, M. (2006). Benefiting from innovation: Value creation, value appropriation and the role of industry architectures. Research Policy, 35(8), 1200-1221.

Johnston, W., Leach, M., \& Liu, A. (1999). Theory testing using case studies in business to-business research. Industrial Marketing Management, 28(3), 201-213.

Johnstone, S., Dainty, A., \& Wilkinson, A. (2009). Integrating products and services through life: An aerospace experience. International Journal of Operations \& Production Management, 29(5), 520-538.

Kindström, D., \& Kowalkowski, C. (2014). Service innovation in product-centric firms: A multidimensional business model perspective. Journal of Business and Industrial Marketing, 28(2), 96-111.

Lee, T. (1999). Using qualitative methods in organizational research. Thousand Oaks: Sage 
Publications.

Meredith, J. (1998). Building operations management theory through case and field research. Journal of Operations Management, 16(4), 441-454.

Meyer, M., \& Lehnerd, A. (1997). The power of product platforms. New York: Simon and Schuster.

Miles, M., \& Huberman, A. (1994). Qualitative data analysis: An expanded sourcebook. Sage.

Muller, E., \& Zenker, A. (2001). Business services as actors of knowledge transformation: The role of KIBS in regional and national innovation systems. Research Policy, 30(9), 1501-1516.

Nambisan, S., \& Sawhney, M. (2011). Orchestration processes in network-centric innovation: Evidence from the field. Academy of Management Perspectives, 25, 40-57.

Nordin, F., \& Kowalkowski, C. (2010). Solutions offerings: A critical review and reconceptualisation. Journal of Service Management, 21(4), 441-459.

Paquin, R., \& Howard-Grenville, J. (2013). Blind dates and arranged marriages: Longitudinal processes of network orchestration. Organization Studies, 34(11), 1623-1653.

Pawar, K., Beltagui, A., \& Riedel, J. (2009). The PSO triangle: Designing product, service and organisation to create value. International Journal of Operations \& Production Management, 29(5), 468-493.

Pekkarinen, S., \& Ulkuniemi, P. (2008). Modularity in developing business services by platform approach. The International Journal of Logistics Management, 19(1), 84-103.

Perks, H., Kowalkowski, C., Witell, L., \& Gustafsson, A. (2017). Network orchestration for value platform development. Industrial Marketing Management, 67, 106-121.

Powers, T., Sheng, S., \& Li, J. (2016). Provider and relational determinants of customer solution performance. Industrial Marketing Management, 56, 14-23.

Raja, J., \& Frandsen, T. (2017). Exploring servitization in China: Challenges of aligning motivation, opportunity and ability in coordinating an external service partner network. International Journal of Operations \& Production Management, 37(11), 1654-1682.

Richard, P., \& Devinney, T. (2005). Modular strategies: B2B technology and architectural knowledge. California Management Review, 47(4), 86-113.

Rowley, J. (2007). The wisdom hierarchy: Representations of the DIKW hierarchy. Journal of Information Science, 33(2), 163-180.

Saccani, N., Visintin, F., \& Rapaccini, M. (2014). Investigating the linkages between service types and supplier relationships in servitized environments. International Journal of Production Economics, 149, 226-238.

Saldaña, J. (2015). The coding manual for qualitative researchers. London: Sage.

Salonen, A., \& Jaakkola, E. (2015). Firm boundary decisions in solution business:
Examining internal vs. external resource integration. Industrial Marketing Management, 51, 171-183.

Salonen, A., Rajala, R., \& Virtanen, A. (2018). Leveraging the benefits of modularity in the provision of integrated solutions: A strategic learning perspective. Industrial Marketing Management, 68, 13-24.

Sawhney, M. (1998). Leveraged high-variety strategies: From portfolio thinking to platform thinking. Journal of the Academy of Marketing Science, 26(1), 54-61.

Schilling, M. (2000). Toward a general modular systems theory and its application to interfirm product modularity. Academy of Management Review, 25(2), 312-334.

Simonin, B. (1999). Ambiguity and the process of knowledge transfer in strategic alliances. Strategic Management Journal, 595-623.

Storbacka, K. (2011). A solution business model: Capabilities and management practices for integrated solutions. Industrial Marketing Management, 40(5), 699-711.

Thomas, L., Autio, E., \& Gann, D. (2014). Architectural leverage: Putting platforms in context. The Academy of Management Perspectives, 28(2), 198-219.

Tilson, D., Lyytinen, K., \& Sørensen, C. (2010). Research commentary-Digital infrastructures: The missing IS research agenda. Information Systems Research, 21(4), 748-759.

Tiwana, A., \& Konsynski, B. (2010). Complementarities between organizational IT architecture and governance structure. Information Systems Research, 21(2), 288-304.

Tiwana, A., Konsynski, B., \& Bush, A. (2010). Research commentary-Platform evolution Coevolution of platform architecture, governance, and environmental dynamics. Information Systems Research, 21(4), 675-687.

Valtakoski, A. (2017). Explaining servitization failure and deservitization: A knowledgebased perspective. Industrial Marketing Management, 60, 138-150.

Voss, C., \& Hsuan, J. (2009). Service architecture and modularity. Decision Sciences, 40(3), $541-569$.

West, J. (2003). How open is open enough?: Melding proprietary and open source platform strategies. Research Policy, 32(7), 1259-1285.

West, J., \& O'Mahony, S. (2008). The role of participation architecture in growing sponsored open source communities. Industry and Innovation, 15(2), 145-168.

Windahl, C., \& Lakemond, N. (2010). Integrated solutions from a service-centered perspective: Applicability and limitations in the capital goods industry. Industrial Marketing Management, 39(8), 1278-1290.

Yin, R. (2003). Case study research. Vol. 5 (Thousand Oaks, California).

Zhang, M., Zhao, X., Voss, C., \& Zhu, G. (2016). Innovating through services, co-creation and supplier integration: Cases from China. International Journal of Production Economics, 171, 289-300. 